\title{
Professor Kyu-Chang Wang: President of the ISPN, 2012-2013
}

\author{
Seung-Ki Kim
}

Received: 25 March 2014 / Accepted: 19 May 2014

(C) Springer-Verlag Berlin Heidelberg 2014

When my mentor Kyu-Chang Wang (Fig. 1) asked me to write his biography last autumn, I was initially taken aback because writing someone's biography is something that I had never done before. Because I have great admiration for Kyu-Chang Wang, I definitely needed time to think before I said yes. However, it did not take long before I agreed to do it. I decided to write his biography for two reasons. First, Kyu-Chang Wang's story is well worth telling, not only because he is a highly acclaimed, prominent scholar but also because, for me, he is a spiritual leader. He is the pediatric neurosurgeon who has shown me the profound words of Bach, the victorious laughter of Mozart, and the intense fire of Beethoven. Second, I have had the privilege of sharing a close relationship with him for a long time, and the impact he has had on my career and on me personally over the years has been truly amazing. I am quite honored and excited to share the life of Kyu-Chang Wang.

Kyu-Chang Wang was born in Seoul, Korea, on November 1, 1954, as the youngest of three children. His family name "Wang" has its origin in the Goryeo dynasty, the second to the last dynasty in Korea. The word "Korea" (many can see the resemblance) comes from "Goryeo." Kyu-Chang's father was a businessman and later became the president of a company affiliated with the Tongyang Group, one of the largest cement-producing companies at the time. His mother was an elementary school teacher. His birthplace is an old town named Sogyeok-dong, Jongno-gu, near Kyungbok Palace. He enrolled in Kyunggi High School, which was one of the most competitive and prestigious schools at the time. In

\section{S.-K. $\operatorname{Kim}(\bowtie)$}

Division of Pediatric Neurosurgery, Seoul National University Children's Hospital, Seoul National University College of Medicine, 101 Daehak-ro, Jongno-gu, Seoul 110-744, Republic of Korea e-mail: nsthomas@snu.ac.kr
Korea, high school students could choose from two academic paths: liberal arts or science. Kyu-Chang chose the science program, which was a very brave decision to make because his father had always wanted his son to become a businessperson or a diplomat. His older brother studied business at Seoul National University, as their father had wished, but dropped out of the School of Business and entered the College of Medicine after retaking the college entrance exam. His brother ended up as an internal medicine practitioner in New Jersey, USA. KyuChang had some conflicts with his father regarding his decision to choose the science program. Fortunately, however, this father-son conflict was resolved by his older sister, who was the apple of their father's eye. In fact, his father, who was a successful businessman, influenced his decision. Kyu-Chang did not like the dog-eat-dog business world where people act according to business principles rather than out of the goodness of their hearts. Furthermore, the subjects in school that he was both passionate for and talented at were mathematics and physics, and this passion and talent formed the basis for his decision to go to medical school. Kyu-Chang was a model student who excelled in almost every subject. His biggest passion was athletics, although he was not cut out for it. He also loved music, even though he had little talent for playing instruments. He played the piano a little and was fairly good with the guitar, but he had to give up further study because it took too much of his time, which was supposed to go toward studying other major subjects. He enjoyed spending a lot of time at temples when he was in his second year of high school. The time that he spent at the temples was so memorable for him that he still remembers those stars at night, the crisp air, the clean water, the candlelight, the smell of the temple, the prayer at dawn, the firewood, climbing the rocky mountain, and the time studying, as if he were there just yesterday. 


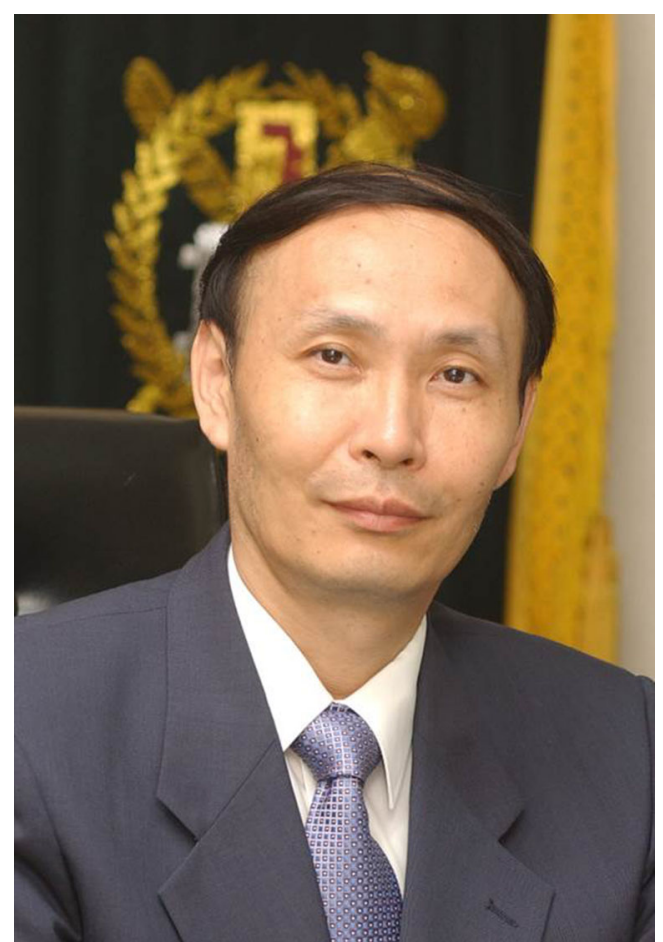

Fig. 1 Portrait of Kyu-Chang Wang

When he was a senior, he served as student body president. Although he was physically weak during his high school years, he earned others' respect with his integrity and academic excellence, which were illustrated by a perfect attendance record and superb grades. Just before taking the preliminary college examination, however, he suffered from glomerulonephritis. Almost everyone advised him to give up on the examination and rest. However, he persevered, took the examination, and was eventually admitted to Seoul National University, College of Medicine with honors.

During college, Kyu-Chang Wang pursued his interests in music, theater, and soccer. He played the oboe in the Medical Orchestra and joined the theater club and a soccer club. He played the "Concerto for Violin and Oboe" by Bach in a musical contest for non-music major students. After winning his first major competition, Kyu-Chang was invited by Bong-Cho Jeon, the Dean of the College of Music, to enroll in the College of Music as a special student. While he was working as a stage director in the theater club, he met Eun-Mi Jung, a talented actress and a junior medical student 1 year younger. They married in 1981 while KyuChang was in his second year of residency in the Department of Neurosurgery. Eun-Mi Jung is a sensitive and calm woman, but in the rare event of an argument, she always wins. She is now a radiologist. Eight years after they married, they gave birth to a son, Tae-Ho Wang (Fig. 2). Tae-Ho, just like his own father, was not a huge fan of his parents' job; he graduated from the

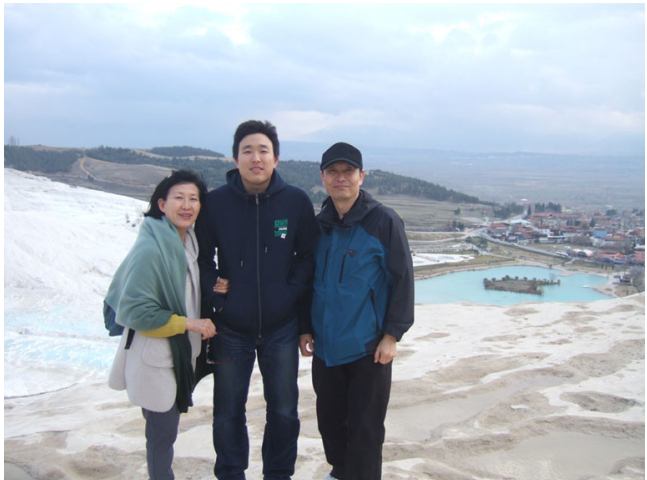

Fig. 2 Family tour in Turkey, 2012. From left, Eun-Mi Jung (wife), TaeHo Wang (son), and Kyu-Chang Wang. In Korea, a woman does not need to change her surname to her husband's after marriage

Department of Mathematical Sciences, Korea Advanced Institute of Science and Technology (KAIST), and became an analyst for Samsung Securities. As much as Kyu-Chang was interested in a variety of extracurricular activities, he maintained a high academic performance and graduated in 1979 and received the Dean's Award, the second highest honor. When he became the Dean of the College of Medicine at Seoul National University, he presented the award at the graduation ceremony that he had won 23 years prior. At the time, Kyu-Chang humorously said "Well, I received this very award when I was graduating. Congratulations."

After Kyu-Chang Wang completed his internship and resident training at Seoul National University Hospital, as well as the 3 years of military service, which is required of all young men in Korea, the time came for him to choose his subspecialty. One day, Professor BoSung Sim (Fig. 3), the founder of the Department of Neurosurgery at Seoul National University Hospital, asked him "What do you think about pediatric neurosurgery?" Pediatric neurosurgery would not have been Kyu-Chang's first choice, as he had more interest in vascular, tumor, and stereotactic neurosurgery. However, he soon changed his mind and decided to choose pediatric neurosurgery as his subspecialty for several reasons. First, Kyu-Chang did not want to disappoint Professor Sim, who had made the suggestion to him. Second, Kyu-Chang knew that it would be a great learning experience to work with someone he wholeheartedly admired, such as Professor Byung-Kyu Cho (Fig. 3). In addition, he did not mind researching pediatric neurosurgery as long as the focus was not on congenital lesions. Rather, brain tumors, hydrocephalus, and moyamoya disease were more appealing to KyuChang. Most importantly, he knew that pediatric neurosurgery would give him opportunities to cure children, which would be meaningful. Kyu-Chang's decision to focus on pediatric neurosurgery under Professor Cho 
Fig. 3 Professor Bo Sung Sim (1924-2001) and Professor Byung-Kyu Cho. Professor Bo Sung Sim (left), Kyu-Chang's big boss and the founder of the Department of Neurosurgery at the Seoul National University Hospital, suggested to KyuChang that he specialize in pediatric neurosurgery. Professor Byung-Kyu Cho (right), KyuChang's boss and the founder of the Division of Pediatric Neurosurgery at Seoul National University Children's Hospital, suggested to Kyu-Chang that he study congenital anomalies
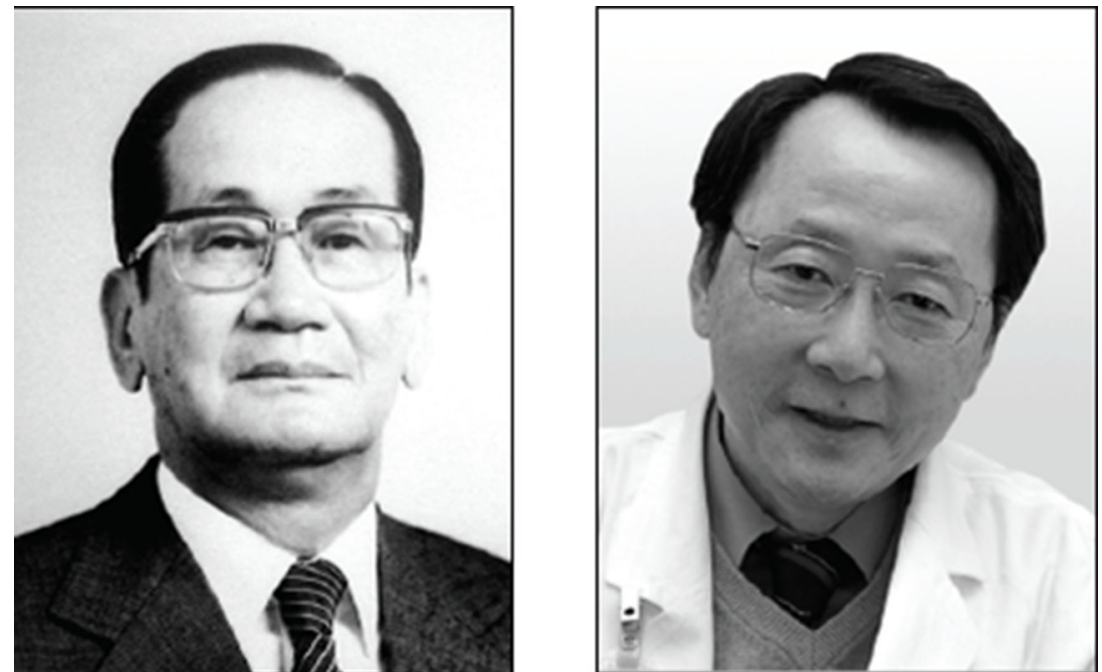

turned out to be a critical turning point in his life. What makes Kyu-Chang even more outstanding is that he became a professor without working as a fellow trainee, which is a typical stepping stone before one reaches the position. After he was discharged from the military, he worked for 4 months without pay until he was appointed. During this 4-month period, he put all of his energy into research. In 1987, he became a member of the faculty of the Department of Neurosurgery in the College of Medicine at Seoul National University.

In 1990, Kyu-Chang Wang had to choose his subsubspecialty before leaving for the USA to study for 2 years. Initially, he considered pediatric brain tumors because, at that time, there had been remarkable achievements in the research on pediatric brain tumors, especially for cases involving medulloblastoma, craniopharyngioma, pineal tumor, and germ cell tumors. In addition, interest was growing significantly in tumor molecular biology and culture technique. However, in contrast, the reality of congenital anomalies was somewhat depressing, given the problems of long-term residual deficits even after adequate treatment, the prolonged course of observation with complications for many organ systems, and the lack of surgical specimens for basic research when compared with tumor surgery. One day, Professor Byung-Kyu Cho, Kyu-Chang's supervisor and the founder of the Division of Pediatric Neurosurgery at Seoul National University Children's Hospital, told Kyu-Chang to go to Chicago to study congenital anomalies, saying "Brain tumors can be studied by any adult neurosurgeon, but the congenital lesions must be dealt with by pediatric neurosurgeons. We should prioritize studying congenital anomalies." Kyu-Chang Wang was so convinced by his words that he chose congenital lesions as his sub-subspecialty and left Korea for Chicago (Fig. 4). From 1990 to 1992 , Kyu-Chang Wang worked as a research fellow under the guidance of Dr. David G. McLone at Children's Memorial Hospital in Chicago. He observed clinical activities in pediatric neurosurgery, including a spina bifida clinic and a camp program. He also took an active part in the laboratory research of open neural tube defect, Chiari malformation, and hydrocephalus.

When he returned to Korea, in 1993, he started a spina bifida clinic and collaborated in clinical and laboratory activities. At the spina bifida clinic, a patient could visit multiple departments and take radiological examinations all in 1 day. Each department was allocated its own room, and a patient could move to the different rooms of each department as needed. He also published a brochure to provide new visitors with detailed information about spina bifida. Furthermore, he inaugurated lectures for parents, released informational newsletters, and hosted camps. The spina bifida camp was designed not only to share basic knowledge and information but also to help provide encouragement, sympathy, and comfort to patients and parents over the course of 3 days. He found these activities quite rewarding and fulfilling because he could see people actually being healed and inspired. In retrospect, Kyu-

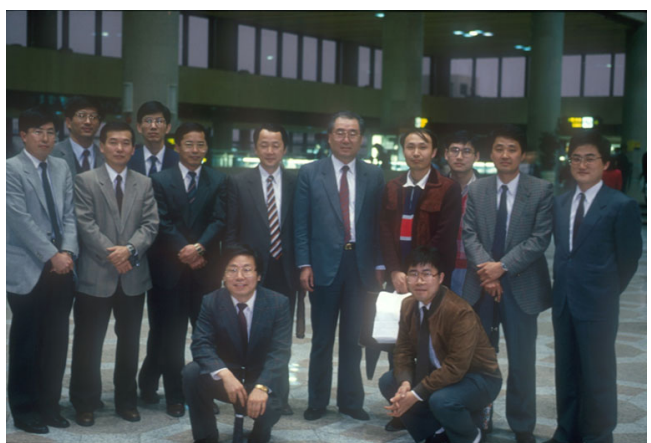

Fig. 4 Kyu-Chang Wang at Gimpo International Airport leaving on a journey to the USA in 1990. His colleagues from the Department of Neurosurgery at Seoul National University Hospital came to give him a send-off (clockwise from top left: Young Seob Chung, Jin Myung Jung, Hee-Won Jung, Kyung Soo Min, Hyun-Jib Kim, Byung-Kyu Cho, Kil Soo Choi, Kyu-Chang Wang, Jeong Hoon Kim, Sun Ho Lee, Jong-Soo Kim, Sun Ha Paek, and Eun-Sang Kim) 
Chang is confident that his choice of congenital anomaly as his sub-subspecialty was worth it.

In 1998, Kyu-Chang Wang was appointed Director of the Department of Research Planning and Management, Clinical Research Institute (now renamed as the Biomedical Research Institute) at Seoul National University Hospital. He then became actively involved in laying the groundwork for the Clinical Research Institute and ensuring the stable operation of the institute. In 2002, he became Director of the Department of Education and Training at Seoul National University Hospital. His many achievements include residents' open recruitment to non-Seoul National University College of Medicine graduates, the establishment of public space ownership for a night duty room and conference room in the hospital, the creation of an intravenous sampler, and efforts to reduce the duration of the residents' assigned work in affiliated hospitals. He initiated the opening of the Medical Research Collaborating Center (MRCC) to provide high-quality research services and education and to serve as a coordinating center for largescale multicenter clinical trials and epidemiologic studies. He also played an important role in the opening of the Seoul National University Bundang Hospital.

In 2004, Kyu-Chang Wang was elected the Dean of the Seoul National University College of Medicine through the direct vote of all professors (Fig. 5). He was the youngest dean ever elected in the history of the Seoul National University College of Medicine. While some professors expressed concerns over Kyu-Chang's service in such a position with enormous responsibilities given his relatively young age, he showed outstanding leadership and successfully accomplished daunting tasks. He endeavored to cultivate harmonious relations among the College of Medicine and Hospital, the alumni association, other medical colleges, and among professors, and he ensured that the members of the College of Medicine could perform at their best by trying to boost morale. All in all, the focus of his effort was to keep modernizing the school facilities and their operations. Kyu-Chang also worked to diversify the source of grants and donations. The

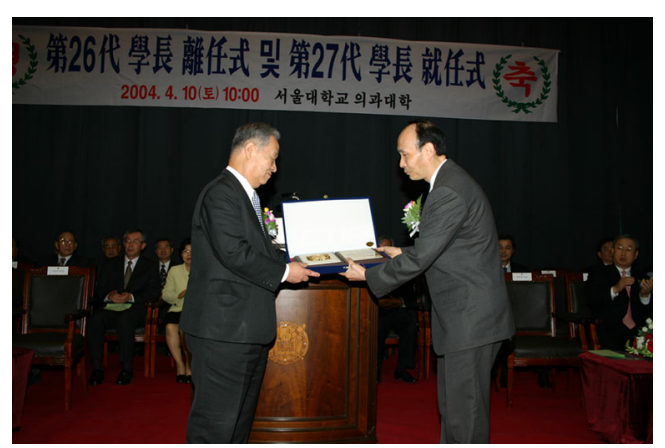

Fig. 5 In 2004, Kyu-Chang Wang was elected the Dean of the Seoul National University College of Medicine (SNUCM) by direct vote of the entire faculty. He was the youngest elected Dean in the history of SNUCM. During his term, he showed youthful leadership mission, vision, and core values of the Seoul National University College of Medicine were mapped out and formulated by Kyu-Chang. The mission of the Seoul National University College of Medicine has become "To make the list of the world's twenty best medical schools by 2017." Additionally, recording the history of the College of Medicine was another task Kyu-Chang has wished to accomplish. In 2005, Korea's then President Moo-Hyun Roh and Seoul National University were in sharp conflict regarding the closure of Seoul National University. The Ministry of Education and Human Resources Development pushed forth the adoption of a medical graduate school in an attempt to reduce the stress of entering medical school and eventually alleviate a competitiveness that had become overheated. However, such a measure would have been nothing more than a stopgap that would have produced an even more chaotic situation. Therefore, Dean Kyu-Chang Wang and the Seoul National University College of Medicine stood up against the government. After much struggle and conflict, the government eventually abandoned its original stance and compromised, deciding to resume the discussion of the physician manpower development system again in 2010. The government also agreed to establish a committee of medical and dental science development. Meanwhile, major medical schools decided to accept the idea to test-run an administration system that allowed for the selection of half of the students from medical schools and the other half from medical graduate schools. Then, in 2010, most medical schools in Korea decided to abolish the medical graduate school system and revert to the conventional medical college system. Dean Kyu-Chang Wang also brought about the socalled public space ownership system, through which the use of certain spaces as meeting rooms came to be managed and supervised by the medical school, not by individual departments, which had been considered less effective. During his term, he strived to secure as much space as possible by assisting in the establishment of the Biomedical Science Building, the Wide River Institute of Immunology, and the renovation of the annex building. He also made significant contribution that took the actual roles and functions of Korean Association of Medical Colleges (KMAC) to the next level. After he finished his 2-year term, he was reappointed after a confidence vote with overwhelming faculty support.

The 38th Annual Meeting of the International Society for Pediatric Neurosurgery (ISPN) was held at Jeju Island, South Korea, from October 30 to November 4, 2010. It was the second ISPN meeting ever held in Korea and the first since the 19th Annual Meeting of ISPN in Seoul in 1991. KyuChang was the ISPN 2010 Meeting Chairman and prepared the agenda of academic and social programs for the conference (Fig. 6). He ensured that participants were updated with cutting-edge knowledge in various fields of pediatric neurosurgery and were able to share their clinical experience. Furthermore, Kyu-Chang hoped the meeting could offer 


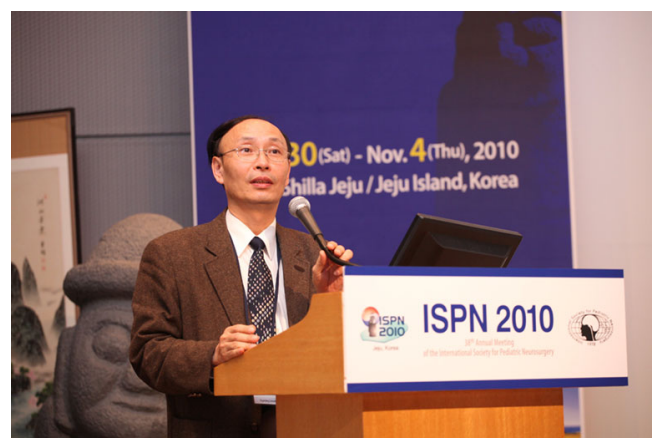

Fig. 6 ISPN's 38th Annual Meeting was held at Jeju Island, Korea, in 2010. Kyu-Chang Wang was the president of the Congress and played host to ISPN members in a variety of academic and social programs, demonstrating Korea's unique hospitality

opportunities for society members to make new acquaintances. The proceedings of the meeting went on to be used to train young neurosurgeons from developing countries through the ISPN-Korean Society for Pediatric Neurosurgery (KSPN) fellowship training programs. In doing so, he wished to return the gifts that Korea had received from the world and give back to human society.

In 2012 at ISPN's Sydney meeting, Kyu-Chang Wang was inaugurated as ISPN's $42 \mathrm{nd}$ president (Fig. 7). In his term, the primary tasks were the academic and educational activities of the ISPN. As these areas were already well established, he promoted the improvement of the operation system of the ISPN, including introducing a standard operating procedure (SOP) system, releasing a newsletter, establishing smooth communication among board members, and creating democratic feedback. He finished organizing the core professional convention organizer (PCO). $\mathrm{He}$ was interested in recording the history of the ISPN. Kyu-Chang's dedication to leadership and responsibility has been seen on many occasions, including the socalled Shanghai Crisis. The 43rd ISPN meeting initially

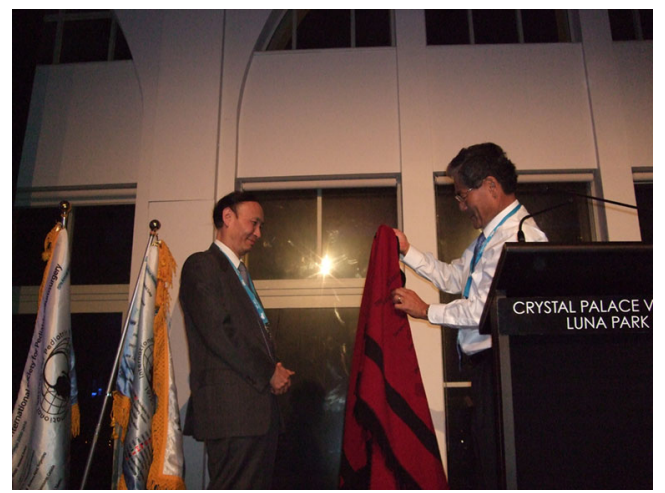

Fig. 7 Kyu-Chang Wang takes over the pancho from the outgoing president of ISPN, Dr. Tadanori Tomita, his predecessor. Here in Sydney, in 2012, he became the 42nd president of the ISPN was to be held in Shanghai. However, conflict loomed as the ISPN 2015 Chinese Organizing Committee stated that "Taiwan" should be addressed as "Taiwan, China" and "Hong Kong" as "Hong Kong, China" on the ISPN webpage as a prerequisite for holding the ISPN 2015 Shanghai meeting. This precondition met with strong opposition from ISPN members. In an effort to overcome this dilemma, Kyu-Chang collected diverse perspectives on the issue and tried to find an alternative solution through negotiation. However, it remains to be seen whether the ISPN 2015 meeting will be held in Shanghai.

At Seoul National University Children's Hospital, Kyu-Chang Wang has regularly mentored medical and undergraduate students, residents, and fellows in clinical inquiry and publication. All papers from the Division of Pediatric Neurosurgery must pass his academic and very rigorous review to survive. This review process is considered to be more difficult than that of the editorial board of any journal. Contrary to his strict academic attitude, he is generous and humorous in private. This character makes him one of the most respected teachers among the students. He has been regularly invited to serve as a visiting professor and as a guest lecturer both nationally and internationally. He has taken a major interest in the international education of neurosurgeons in the field of pediatric neurosurgery. After ISPN 2010 Jeju, he launched the ISPN-KSPN international fellowship program. He actively participates in ISPN educational courses as a lecturer.

Kyu-Chang Wang has been recognized for his excellence in clinical and translational neurosurgery. His main interest is basic research on the spinal open neural tube defect and the application of stem cell therapy. He adopted a chick embryo surgical model and has published many scientific articles on this subject. He and Dr. Dachling Pang are best friends and the experts in this field (Fig. 8). Although his sub-subspecialty is "congenital lesions," his clinical area has broadened to include brain tumors, moyamoya disease, endoscopic surgery, and functional surgery. Based on his surgical experience, Kyu-Chang proposed a novel classification of craniopharyngioma into three categories according to the level of origin and the competence of the diaphragm sellae: a tumor of subdiaphragmatic origin with competent diaphragm sellae, subdiaphragmatic with incompetent diaphragm sellae, and supradiaphragmatic. This classification system is very informative and useful for choosing surgical approaches such as transcranial and transsphenoidal. Kyu-Chang Wang and his colleagues have also developed and described surgical techniques and translational research for moyamoya disease. Thanks to another significant achievement of his, it is 


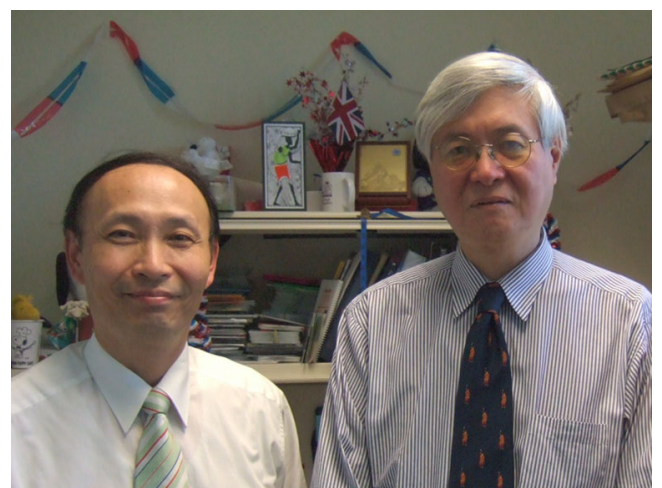

Fig. 8 Kyu-Chang Wang visited Dr. Dachling Pang's institute in 2009. He observed Dr. Pang's radical surgery for lumbosacral lipoma. Dr. Pang introduced the 42nd President Kyu-Chang Wang before his presidential address in Mainz, 2013

now possible to collect tissue samples at the Pediatric Brain Tissue Bank, the establishment of which was proposed by Kyu-Chang.

As a clinician, Kyu-Chang Wang is widely known to be a prudent strategist. He always ensures that the surgical plans are set before operation. These plans include deciding not only how to approach the lesion and what to do but also when to stop (Fig. 9). His meticulous planning and strategic execution make his surgery nothing less than an art form.

The Division of Pediatric Neurosurgery was opened as an independent session from the Department of Neurosurgery in 1982 (Fig. 10). Since 2008, the Division of Pediatric Neurosurgery has been upgraded to the Pediatric Clinical Neuroscience Center (PCNC), Seoul National University Children's Hospital, in collaboration with the Department of Pediatric Neurology, Pediatric Neurosurgery and Pediatric Rehabilitation Medicine (Fig. 11). The core values of this center are best care, excellence, innovation, contribution, and partnership. This center aims to achieve the most advanced level of practice, agreement between basic science and clinical research, and

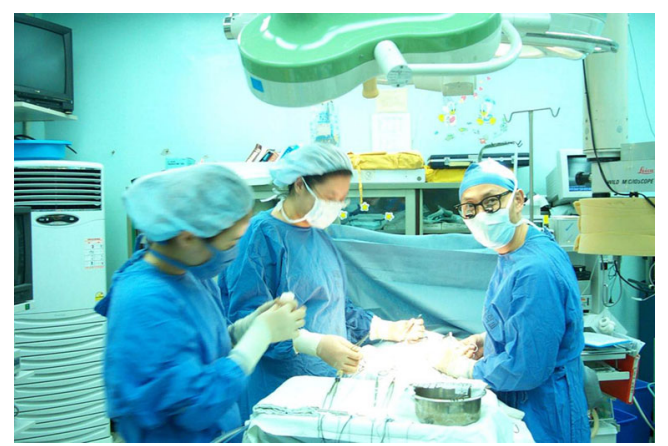

Fig. 9 Spinal anomaly operation performed by Kyu-Chang Wang. Although he initially declined to specialize in pediatric neurosurgery or congenital lesions, caring for children with congenital anomalies became his true calling

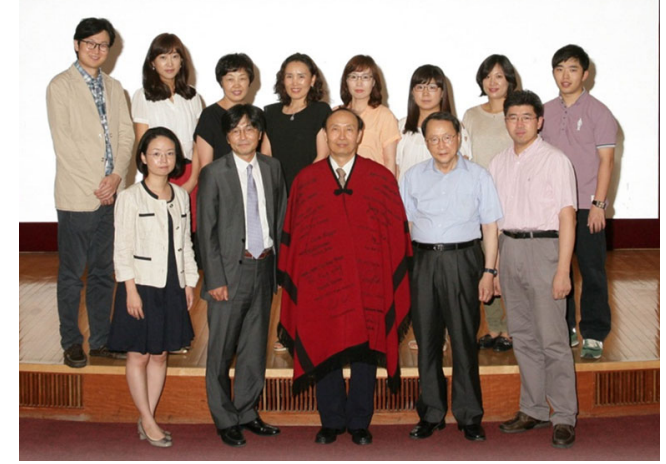

Fig. 10 The Division of Pediatric Neurosurgery was established at Seoul National University Hospital in September 1982. Over 30 years, the division has established and upgraded its clinic, education, and research potential. Members of the Division of Pediatric Neurosurgery took this photograph to celebrate their 30th anniversary (clockwise from top left: Jung Won Choi, Tae Hee Kang, Myung Sook Lee, Hyun Hwa Kim, Jang Mi Lim, Young Hee Kim, Mi Sun Park, Seul Ki Ryu, Ji Hoon Phi, Byung-Kyu Cho, Kyu-Chang Wang, Seung-Ki Kim, and Ji Yeoun Lee)

innovative educational program to fulfill its core values for pediatric patients with neurologic problems.

Kyu-Chang Wang is not only an excellent educator, researcher, and clinician but also a highly talented and efficient administrator. Kyu-Chang led the Seoul National University College of Medicine over 4 years. His leadership deeply moved the members of the College of Medicine. As the youngest elected dean, he showed youthful ambition and a strong capacity for execution. He never yielded to the government's unreasonable demands. Many colleagues around him are pushing KyuChang Wang to lead Seoul National University as a president. However, he has a different idea for his life. He would like to begin accomplishing the goals on his bucket list, which include creating a comprehensive summary of the clinical cases he has experienced,

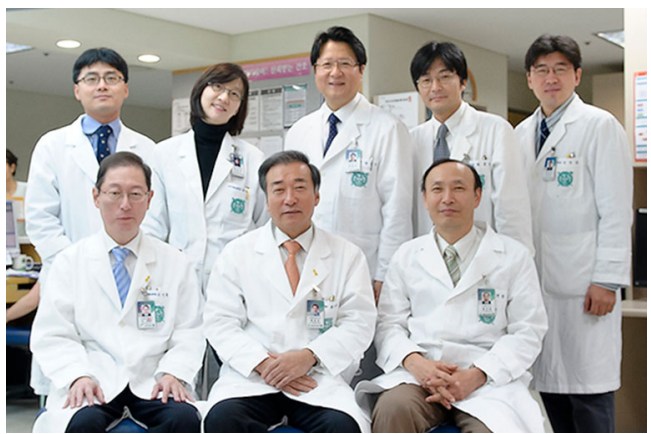

Fig. 11 The Pediatric Clinical Neuroscience Center was opened at the Seoul National University Children's Hospital in 2008. This center is composed of pediatric neurology, pediatric neurosurgery, and pediatric rehabilitation medicine. They provide integrated medical service and pursue innovative research for children with neurological disease (clockwise from top left: Byung Chan Lim, Jong Hee Chae, Moon Suk Bang, Seung-Ki Kim, Ji Hoon Phi, Kyu-Chang Wang, Yong-Seung Hwang, and Ki Joong Kim) 


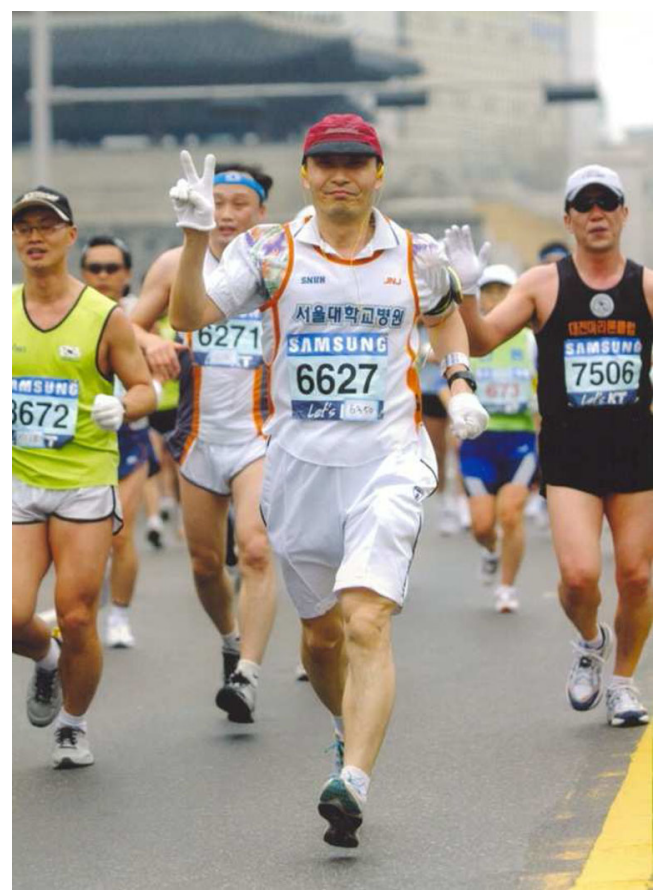

Fig. 12 Kyu-Chang Wang is an avid marathoner. He says what makes marathons so special is that they do not require brains or money. He loves the sport because it gives him the opportunity to enjoy beautiful scenery, listen to music, and put his thoughts together, all at the same time

including his own personal opinions. The list also includes writing essays and his autobiography, expressing his heartfelt gratitude to those he admires and cherishes, as well as to those to whom he owes so much. He is also excited to spend more time playing musical instruments, such as the oboe or piano, and he would love to immerse himself in music and relax. Sports, such as marathon running (Fig. 12), have been in his mind for a long time, along with learning foreign languages and embarking on a voyage.

Kyu-Chang Wang is undoubtedly a powerful man who should fear no enemy. However, what makes him truly the man is his ability to make friends with people from all walks of life, even including his enemy. Other than all those great qualities that have made him what he is today, what strikes the deepest chord in our hearts is what he said when he was asked to leave a message for his younger students.

You don't need to be the first place winner all the time to prove your excellence; you only have to prove it to yourself, living up to or beyond the standards you set for yourself. There is nothing wrong with having a lessthan-specific goal, as long as the goals you set are for both the present and the future. Be careful not to hurt other people's feelings, even inadvertently. Try to pursue a happy and rewarding life where you find yourself sharing happiness with others.

Acknowledgments I deeply appreciate Bo-Young Lee and Eui Joon Kim for the English editing of this article. 